\title{
Preoperative Patient Assessment Practices: A Survey of Kenyan Perioperative Nurses
}

\author{
Lilian A. Omondi \\ School of Nursing Sciences, College of Health Sciences, University of Nairobi, Nairobi, Kenya \\ Email address: \\ liliathis@gmail.com \\ To cite this article: \\ Lilian A. Omondi. Preoperative Patient Assessment Practices: A Survey of Kenyan Perioperative Nurses. American Journal of Nursing \\ Science. Vol. 5, No. 5, 2016, pp. 185-190. doi: 10.11648/j.ajns.20160505.13
}

Received: September 1, 2016; Accepted: September 9, 2016; Published: September 28, 2016

\begin{abstract}
Background: Patients undergoing surgery are at risk of developing complications related to surgery and anesthesia amidst heightened anxiety. The key roles played by perioperative nurses in surgery, mandate them to conduct preoperative patient assessment to identify and mitigate potential complications and to plan and deliver quality perioperative care. However, paucity of literature evidencing the practice is very low. Objective of this survey was to evaluate the assessment practices among Kenyan perioperative nurses. Design: A countrywide cross section descriptive survey. Results: Seventy two Kenyan perioperative nurses among conference attendees consented and participated in the survey. Allthe participants were registered nurses out of who only $13(18.1 \%)$ had trained in perioperative nursing specialty at diploma level. Out of the 13 trained, only $3(4.2 \%)$ had Bachelor of Science degree in nursing. Although preoperative patient assessment was reported to be practiced 58 $(80.5 \%)$ it was apparent that the practice varied with individuals and institutions. Regarding the details of the assessment, general condition of patients, physical, physiological and psychological aspects come out strongly but not the emotional, spiritual and cultural aspects of the patients. Verbal and written reports were reported to be the main modalities of disseminating assessment feed backs to other nurses especially during shift handing over reports. Although preoperative assessment was undoubtedly reported to be beneficial in improving patients' care $42(58.3 \%)$ however, only $2(2.8 \%)$ indicated its use in planning patients' care. Conclusion: In spite the findings, some glaring gaps likely to impact on quality of nursing care do exist in the preoperative assessment practices by perioperative nurses in Kenya.
\end{abstract}

Keywords: Perioperative Patient Assessment, Preoperative Ward Visits, Perioperative Nurses, Practice, Kenya

\section{Introduction}

Patient-centered preoperative assessments by perioperative nurses gather critical data which when used to develop and implement nursing care plans optimizes patients' surgical care [18]. Effective preoperative patient assessment encompasses holistic patient's care aspect that includes physical, physiological, psychological, socio-cultural, emotional, spiritual and individual surgical needs $[1,2,18]$. Traditionally, preoperative ward visit to collect data at the patients' bedside or in the clinic in elective surgeries gave perioperative nurses time to directly observe and learn patients' behavior [3]. Perioperative nurses and patients got acquainted during the visits in such a way that patients' developed mutual trust that empowered them to express their concerns about the impending surgery, a process which also allayed their anxieties[1].In emergency situations, preoperative assessment is done when the patient is already in theatre because of time constraints. Nevertheless, patients' teaching and care plans and preparation must be as thorough as possible [4].

In the developed countries, preoperative patient assessment for elective surgery is mainly done in pre-surgical clinics by physicians, anesthetists and registered nurses. In Kenya, surgeons perform the assessment at the clinics or surgical wards. Perioperative nurses and anesthetists/anesthesiologists conduct the assessment independently through ward visits, the evening or night before surgery. Performing preoperative wards visits to conduct preoperative patient assessment is quite challenging. Limited nursing staffing in most surgical setups, changes in patients' surgical admission patterns, and the busy theatre schedules have made the timing of preoperative visits unpredictable and unfavorable among perioperative nurses[5],[6], [7], [8]. This explains the low documented 
preoperative assessment practice among perioperative nurses as a result of lack of clinical evidence [9], [10], [11].

More than 234 million surgical procedures are performed globally each year [12]. According to [13], patients undergoing surgery are at high risk of developing complications including death relating to surgery and anesthesia. Patients' Bill of Rights and Joint Commission for Accreditation of Health Care Organizations (JCAHO) dictates that all patients have a right to quality care [2]. In this regard, preoperative patient assessment is not only a strategy to mitigate abatable risks predisposition to surgical patients but a roadmap for enhancing care proficiency and patients' surgical safety. Therefore, the aim of the survey was to assess preoperative assessment practices among Kenyan perioperative nurses.

\section{Methodology and Tools}

\subsection{Design}

This was a nationwide survey of preoperative assessment practices among perioperative nurses in Kenya.

\subsection{Study Area}

The survey was conducted at the $54^{\text {th }}$ Annually Scientific Conference held from $1^{\text {st }}$ to 5 thNovember 2011 at Kenya School of Journalism situated in South C, Nairobi, Kenya. The conference was an annual event organized by the National Nurses Association of Kenya through the Theatre Chapter as a forum for engaging in matters regarding education and research, clinical practice and welfare related concerns. Usually the conference attracts nurses from various private, public and faith based hospitals in Kenya and other neighboring African countries like Tanzania, Uganda, Zambia, Malawi, and Mozambique among other African countries.

\subsection{Study Population}

All nurses who attended the conference.

\subsection{Inclusion/Exclusion Criteria}

Only nurses working in Kenyan public, private and faith based surgical settings were eligible to participate. Nurses not working in Kenyan operating theatres were exempted from participation.

\subsection{Sampling Technique Purposive}

Purposive sampling was employed and 72 perioperative nurses among the conference attendees were censured.

\subsection{Data Collection Procedure and Tools.}

Self administered structured questionnaires with open and closed ended questions were administered by the researcher among perioperative nurses meeting the inclusion criteria as was programmed in the conference schedule and received back.

\subsection{Data Analysis and Management}

Quantitative data from closed ended questions was analyzed using statistical package for social sciences (SPSS) version 17 and presented as frequencies. Qualitative data from the open ended question was grouped in themes and summarized as reported narrative.

\subsection{Ethics}

Ethical approval was obtained from Kenyatta National Hospital and University of Nairobi Ethical Review Board. Permission to engage the nurses during the conference was obtained from Chairman of National Nurses Association of Kenya through the Chairman of Theatre Chapter. Participation was voluntary and all the participants gave informed verbal and written consents before participation. All ethical principles were observed.

\section{Results}

\subsection{Demographic Characteristics}

Table 1. Demographics of the participants.

\begin{tabular}{lll}
\hline Demographic variable & No of respondents & Percentage \\
\hline Gender & 23 & 31.9 \\
male & 48 & 66.7 \\
Female & 1 & 1.4 \\
No response & & \\
Age in years & 31 & 43.1 \\
25-34 & 27 & 37.5 \\
30-44 & 7 & 9.7 \\
45-59 & 7 & 9.7 \\
No response & & \\
Professional qualification & & 69.4 \\
RN & 50 & 13.9 \\
RN + ORN & 10 & 4.2 \\
BSCN + ORN & 3 & 12.5 \\
No response & 9 & \\
Work experience & & 15.3 \\
> 1year & 11 & 52.8 \\
1-5years & 38 & 18.1 \\
6-10 years & 13 & 11.1 \\
< 10years & 8 & 2.8 \\
No response & 2 & \\
\hline
\end{tabular}

Key: RN- Registered Nurse; ORN- Operating Room Nurses (perioperative nurses); BScN- Bachelor of Science Degree in Nursing.

\subsection{Provinces}

Kenya had 8 provinces currently subdivided into 47 counties after adoption of devolution system of governance in Kenya. Seven out of the eight provinces were represented 
in the survey, Figure 1.



Figure 1. Provinces represented by the perioperative nurses.

\subsection{Surgical Settings}

The participants were from different institutions. Majority $44(61.1 \%)$ were from public institutions at various levels of health care delivery while $28(38.9 \%)$ were from various levels of private institutions including faith based hospitals, Table 2 .

Table 2. Surgical setting represented by the perioperative nurses.

\begin{tabular}{lll}
\hline Surgical setting $(\mathbf{n}=\mathbf{7 2})$ & No. of respondents & Percentage \\
\hline $\begin{array}{l}\text { i. Referral hospitals and equivalent } \\
\text { Public }\end{array}$ & 14 & \\
$\begin{array}{l}\text { Private } \\
\text { ii. Provincial hospitals and equivalent }\end{array}$ & 10 & 19.4 \\
$\begin{array}{l}\text { Public } \\
\text { Private }\end{array}$ & 3 & 13.9 \\
iii. District hospitals and equivalent & 8 & 4.2 \\
Public & 14 & 11.1 \\
Private & 0 & \\
iv. Others & & 19.4 \\
Public & 13 & 0 \\
Private & 2 & 18.1 \\
No response & 8 & 2.8 \\
\hline
\end{tabular}

\subsection{Preoperative Patient Assessment Practices by Perioperative Nurses}

Participants' response regarding preoperative assessment practices are as shown in Table 3 .

Table 3. Preoperative assessment practices by perioperative nurses.

\begin{tabular}{|c|c|c|c|}
\hline & $\begin{array}{l}\text { Preoperative assessment } \\
\text { practices }(n=72)\end{array}$ & $\begin{array}{l}\text { No. of } \\
\text { respondents }\end{array}$ & Percentage \\
\hline \multirow[t]{3}{*}{ i. } & Do you practice preoperative assessment? & & \\
\hline & Yes & 58 & 80.6 \\
\hline & No & 14 & 19.4 \\
\hline \multirow[t]{4}{*}{ ii. } & How frequent is preoperative assessment $p$ & ractice done? & \\
\hline & Always & 38 & 52.8 \\
\hline & Not always & 20 & 28.8 \\
\hline & No response & 14 & 19.4 \\
\hline \multirow[t]{2}{*}{ iij } & Who does the assessment? $(n=72)$ & & \\
\hline & Theatre nurses & 31 & 43.1 \\
\hline
\end{tabular}

\begin{tabular}{lll}
\hline $\begin{array}{l}\text { Preoperative assessment } \\
\text { practices(n=72) }\end{array}$ & $\begin{array}{l}\text { No. of } \\
\text { respondents }\end{array}$ & Percentage \\
\hline $\begin{array}{l}\text { Surgeons, anesthetists and ward nurses } \\
\text { No response }\end{array}$ & 27 & 37.5 \\
iv Where is the assessment done?(n=72) & 14 & 19.4 \\
In the wards before surgery & 37 & 51.4 \\
In theatre & 16 & 22.2 \\
Other places other than theatre and & 13 & 18.1 \\
wards & 6 & 8.3 \\
No response & & \\
What time is the assessment & & 50 \\
done?(n=72) & 36 & 38.9 \\
No specific time allocated & 28 & 11.1 \\
Specific time allocated & 8 & 47.2 \\
No response & 34 & 41.7 \\
vi Are there policies governing PPA practice?(n=72) & 11.1 \\
Yes & 30 & 37.6 \\
No & 8 & 34.7 \\
No response & 27 & 27.7 \\
vi Do you use a PPA models?(n=72) & 25 & \\
Yes & 20 & \\
No & & \\
No response & & \\
\hline
\end{tabular}

3.5. Summary of Thematic Grouping of Responses $(n=72)$ of Preoperative Patient Assessment Parameters, Table 4.

Table 4. Summarized narration of what is assessed by perioperative nurses.

\begin{tabular}{ll}
\hline $\begin{array}{l}\text { Responses regarding what is assessed in preoperative patient } \\
\text { assessment }\end{array}$ & $\begin{array}{l}\text { Patients' general condition, current and past } \\
\text { medical/surgical history, previous surgeries and } \\
\text { anesthesia experience and food or drug allergies. }\end{array}$ \\
i. General & $\begin{array}{l}\text { Suitability for anesthesia, anesthetic risks, comobidities } \\
\text { and surgical risks. }\end{array}$ \\
& $\begin{array}{l}\text { Systematic head to toe assessment to rule out any scars, } \\
\text { broken skin, assess operation site, pallor on the mucous, }\end{array}$ \\
ii. Physical & $\begin{array}{l}\text { age, weight especially in children, hygiene and } \\
\text { nutritional status }\end{array}$ \\
& $\begin{array}{l}\text { Vital signs to include temperature, pulse, respiration, } \\
\text { blood pressure. } \\
\text { Cardiac evaluation on patients who have cardiac related } \\
\text { iii. Physiological } \\
\text { abnormalities and are in critical conditions at the time }\end{array}$
\end{tabular}




\begin{tabular}{ll}
\hline $\begin{array}{l}\text { Responses regarding what is assessed in preoperative patient } \\
\text { assessment }\end{array}$ & \\
& of admission \\
& Physical preparation e.g. gowning, shaving, consent, \\
& laboratory investigations among other preoperative \\
preparations and completing the preoperative checklists. & \\
& Laboratory investigations to include, blood sugar and x- \\
& rays if required, oxygen saturations in blood $\left(\mathrm{SPO}_{2}\right)$, \\
& hemodynamic stability, hydration status and any other \\
& tests deemed necessary. \\
& $\begin{array}{l}\text { Assessing level of education and knowledge of the } \\
\text { proposed surgery, mental status, psychological }\end{array}$ \\
iv. Psychological & $\begin{array}{l}\text { readiness for surgery. Discussing discharge plan to } \\
\text { include someone to take patient home in day care } \\
\text { surgery. }\end{array}$ \\
\hline
\end{tabular}

\subsection{Preoperative Assessment Information Documentation}

Only $23(31.9 \%)$ respondents indicated that preoperative assessment feedback was documented in all the relevant patients' documents. The rest $49(76.1 \%)$ gave varying responses, Figure 2.

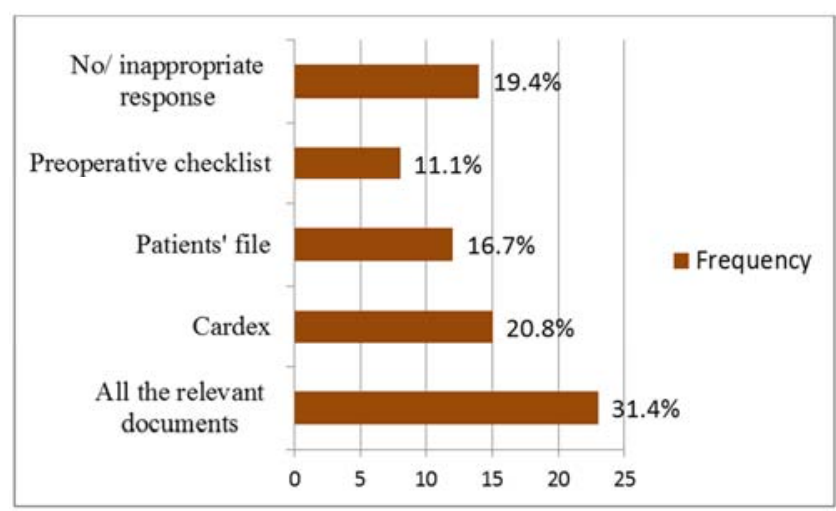

Figure 2. Responses on where assessment information is documented.

\subsection{Dissemination of Preoperative Patient Assessment Feedback}

Verbal and written reports are the main dissemination modalities used by the nurses to disseminate information especially when handing over from one shift to another, Figure 3.

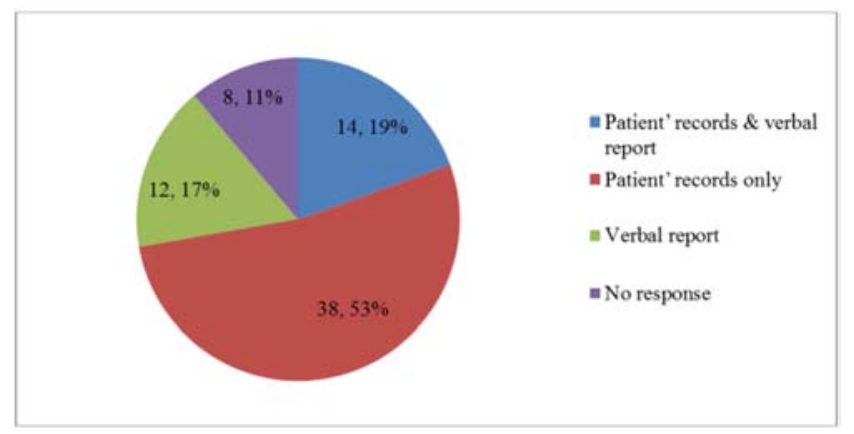

Figure 3. How others get assessment feedback $(n=72)$.

\subsection{Preoperative Assessment Information Utilization}

Forty two $(58.3 \%)$ participants reported that the assessment report is used to facilitate patients' care, only 2 $(2.8 \%)$ indicated that the information is mainly used to plan patients' care. Other responses indicated use as protocol $2(2.8 \%)$, as baseline information $4(5.6 \%), 5(6.9 \%)$ to make judgment while $17(23.6 \%)$ gave no response.

\subsection{Benefit(s) of Preoperative Patient Assessment}

Most participants 66(91.7\%) agreed that the assessment was beneficial to the patient while $6(8.3 \%)$ did not respond. The cited benefits included to improve direct patient care $56(77.8 \%)$, to improve surgical care $8(11.1 \%)$ and to correct abnormalities encountered $2(2.8 \%)$.

\section{Discussion}

Majority of the participants were mainly female $48(66.7 \%$, $\mathrm{n}=72$ ). This can be attributed to the fact that nursing was originally a female dominated career both in Kenya and globally. The female dominance exists even in the operating theatres [14]. Regarding age distribution, 58(80.6\%) were aged between $25-44$ years old and $49(68.1 \%)$ had less than five years working experience. This can be explained by the high attrition rate of experienced nurses to the developed countries and work related stress in theatre among other reasons [15].The results showed that very few nurses working in theatre were trained in perioperative nursing $13(18.1 \%, \mathrm{n}=72)$. At the time the survey was undertaken, there were only $175 \mathrm{ORNs}$ and $12 \mathrm{BScNs}$ trained nationally in perioperative nursing according to the nursing regulatory body register of 2011. Moreover, there were only two perioperative nursing training schools nationwide. The two schools had annual training capacity of not more than 20 perioperative nurses and had recently been established. A similar survey done in Nigeria revealed same findings and recommended retention of the nurses and mandatory continuous professional education programs training for perioperative nurses to keep abreast with the new trends in perioperative nursing practice [16].

Seven out eight provinces (currently 47 counties) were represented in the study. Notably, one of the provinces (North Eastern province) had no representation because at the time the survey was undertaken, the province was experiencing ethnic clashes. The nurses may have encountered either security challenges impending conference attendance or may have been very busy theatre attending to the clash victims. The participants were from both public and private surgical settings including faith based institutions ranging from major referral hospitals to small private hospitals.

Although preoperative assessment was reported to be practiced $58(81.9 \%, \mathrm{n}=72)$, the practice was varied and congruent to a similar assertion [17]. Various responses were elicited in response to an open ended question poised regarding what was assessed during preoperative patient assessment. It emerged that patients' general condition, physical, physiological, and psychological aspects were 
assessed in tandem with the best practices [1, 2,18]. However, spiritual and emotional aspects did not standout clearly as well as the distinct role of the perioperative nurse during the assessment. These results reflect challenges facing preoperative assessment practices as have already been cited $[7,8]$. Moreover, the concept preoperative ward visit which is a conduit for conducting the assessment is not well understood among perioperative nurses [19-22].

It is encouraging that at least $23(31.9 \%)$ participants indicated documenting preoperative assessment data in all the relevant documents among other responses. Verbal and written reports were the main dissemination modalities used by perioperative nurses to pass over the information to colleagues. Although $42(58.3 \%)$ reported that the assessment report is used for improving patient care, only $2(2.8 \%)$ indicated using the information to plan patients' care. This response poses a dilemma of Hawthorn effect or a pertinent gap in practice. As a matter of fact assessment information should form the baseline data for implementing and evaluating perioperative surgical interventions [23, 24]. Majority of the respondents agreed that conducting preoperative assessment is beneficial to both patients and the institution and has been supported $[1,2,13,18$, 24].

\section{Conclusion}

Preoperative assessment practices among perioperative nurses require mainstreaming and restructuring to enhance care proficiency.

\section{Recommendation}

There is need to enhance professionalism in perioperative nursing practice through

- Increasing perioperative nursing specialty training and sustained updates in practice through continuous professional development initiatives.

- Retention of the trained nurses in the operating theatres to improve and maintain standards of quality practice

- Need to reinforce preoperative patient assessment practices as prerequisite for planning quality care interventions

- Fostering structured preoperative assessment frameworks that will include spiritual, cultural and emotional aspects of holistic patient care crucial during surgery.

- Creating supportive theatre environment to enhance feasibility of sustained preoperative assessment practices through informed policies and improved nursing staffing ratios.

\section{Acknowledgement}

The author is thankful to National Nurses Association of Kenya, Theatre Chapter for the permission and facilitation to collect data during the $54^{\text {th }}$ Annual Scientific conference for Perioperative Nursing.

\section{Conflict of Interest}

The author declares non existence of conflict of interest.

\section{References}

[1] National Association of Theatre Nurses (NATN) (1996). Principles of safe practice in the perioperative environment. Harrogate: NATN.

[2] Rothrock, J. C, \& McEwen D., R. editors. (2007). Alexander's care of the patient in surgery. (15th ed.). St. Louis, MO: Mosby.

[3] Spry, C. (2005). Essentials of perioperative nursing. (3rd ed.). United Kingdom. Jones \& Bartlett Publishers Inc.

[4] Zastrow, S. L., (2009). Perioperative nursing assessments made simple.Nursing4 (3), 16 -17.Retrieved on October 30, 2014 from http://www.Operating room nurse. NurseJournal.com.

[5] Sadati, L., Pazouki, A., Mehdizadeh, A., Shoer, S., \&Tamannaie, Z. (2013). Effect of preoperative nursing visit on preoperative anxiety and postoperative complications in candidates for laparoscopic cholecystectomy: A randomized clinical trial. Scandinavia Journal of Caring Science, (27), 994-998.

[6] Taylor, M., \& Campbell, C. Surgical practice. In: Clarke, P. \&Jones, J. editors. Brigden's Operating Department Practice. Edinburgh: Churchill Livingstone. 1998.

[7] Torrance, C., \& Serginson, E. (1997). Surgical nursing. (12th ed). London: Baillière Tindall.

[8] Coleman M, White J. (2001).Pre-operative visiting in Wales: A study of its prevalence and nature. Journal of Research in Nursing (2), 611-624. Reviewed on June 22, 2016 from http://jrn.sagepub.com/content/6/2/611

[9] Beck, A. (2007). Nurse-led pre-operative assessment for elective surgical patients. Nursing Standard, 21(51), 35-38.

[10] Hines, S., Chang, A., Ramis, M., \&Pike, S. (2010). Effectiveness of nurse-led preoperative assessment services for elective surgery: A systematic review. Joanna Briggs Institute Library of Systematic Reviews, 8 (15), 621-660.

[11] Oakley, M. (2005). Preoperative assessment. In: Pudner, R., editor. Nursing the surgical patient (2nd ed). London: Bailliere Tindall.

[12] Weiser, T.G., \& Regenbogen, S. E., Thompson, K. D., Haynes, A. B., Lipsitz, S. R., \& Berry, W. R., \& Gawande, A.A. (2008). An estimation of the global volume of surgery: A modelling strategy based on available data. Lancet: 372 (9633), 139-44. doi: 10.1016/S0140-6736(08)60878-8.

[13] National Health services (NHS) (2003). Operating theatre and pre-operative assessment program, National good practice guidance on pre-operative assessment for Inpatient Surgery. NHS, London.

[14] Bamishaiye, E. I., Hinmikaiye, C. D. (2012). The incidence of low back pain among theatre nurses: A case study of University of Ilorin and Obafemi Awolowo University Teaching Hospital. International Journal of Nursing Science, 2(3):23-28. doi:10.5923/j.nursing.20120203.02. 
[15] Gbiri, C.A., Osho, A.O., Olumiji, A. (2012.Prevalence, pattern and impact of work-related musculoskeletal disorders on functional performance of welders in a Nigeria rural-urban center. Journal of Occupational Health and Epidemiology1, 87-94.

[16] Danjuma, A, Ibrahim,T.A., Omoniyi, S.O., Kolo, S., Odofin, O.M., et al. (2015) Knowledge, Attitude and Practice of Preoperative Visit: A Survey of Nigerian Perioperative Nurses. American Journal of Health Research 3: 54-60.

[17] Bramhall, J. (2002). The role of nurses in preoperative assessment. Nursingtimes.net 98 (40),34. Retriewed on August 18,2014 from http://www.ncbi.nlm.nih.gov/pubmed/12382440

[18] Association of Perioperative Registered Nurses (AORN) (2012). Perioperativestandards and recommended practices. Denver, CO. Retrieved on September 16, 2016 , http://www.aorn.org/WworkArea/DownloadAsset.aspx?id=21 931.
[19] Kalideen D. (1991). The case for pre-operative visiting. British Journal of Theatre Nursing, 1 (5), 19-21.

[20] Wicker, P. (1995). Pre-operative visiting: making it work. British Journal of Theatre Nursing, 5 (7), 16-19.

[21] Crawford, B. (1999). Highlighting the role of the perioperative nurse - preoperative assessment necessary? British Journal of Theatre Nursing 9 (7), 319-322.

[22] Williams, M. (2002). Preoperative visiting- an urban myth? British Journal of perioperative Nursing, 12 (7), 168.

[23] Malley A., Kenner, C., Kim T., \& Blakeney, B. (2015). The Role of the nurse and the preoperative assessment in patient transitions. Association of perioperative Registered Nurses Journal,102(2),181.e1-181.e9.doi:10.1016/j.aorn.2015.06.004

[24] Phillips, N. (2004). Berry \& Kohn's operating room technique. (10th ed.). St. Louis, Mosby. 